\title{
The State of the Field of Taiwan Studies
}

\section{GUEST EDITORS' INTRODUCTION}

\author{
Hsin-Huang Michael Hsiao and Dafydd Fell
}

States of the field articles can play a crucial role in any academic field. They are unfortunately often undervalued. Such essays are unlikely to contribute to a scholar's bid for promotion or departmental assessment. Having previously written states of the field essays ourselves, we are aware that though it can be rewarding, putting such essays together is also an extremely time consuming process. ${ }^{1}$ Unsurprisingly it can be hard to find scholars that have the enthusiasm and time required to construct such pieces.

Nevertheless, such pieces are extremely valuable for both scholars and students. Of course, we can get a long list of related publications by doing an online database search, but this is just a list and will not give us a sense of how individual publications fit into a field and how they have been received by academic peers. When a PhD student or scholar embarks on a new research project, a key initial step is to get a critical perspective on what has been done before. Then their task will be to challenge and build upon this existing literature in order to make an original contribution to their respective fields. As PhD examiners or book reviewers, a key element that we look for is the degree that an academic work not only builds on and engages with existing literature but also offers an original contribution to the field. Good state of the field essays can help PhD students build up their sound literature reviews and avoid getting lost in the midst of crowded literatures.

States of the field are also invaluable for teachers that are looking to design academic courses or who wish to update their existing courses. This is particularly true of junior academic who are facing the daunting task of writing their first set of lecture notes and course reading lists. Junior academics are often pressured to teach courses they are not necessarily familiar with and thus state of the fields can offer a crucial shortcut for course preparation. Such pieces are also critically important for undergraduate and postgraduate students. When they come to writing their term papers, they need to cite and potentially critique the most important works within a field in order to develop their own arguments and analysis. Good state of the field essays can help students to know the works they need to engage with and also to avoid misunderstanding works.

Of course, the field of Taiwan Studies does have numerous high quality states of the field essays already. Back in 2002-2004 Issues and Studies published two influential states of the field essays. The first by Shelley Rigger was titled 'Political Science and Taiwan's Domestic Politics: The State of the Field,' while the second by Lee Wei-chin was titled 'Field of Dreams:

\footnotetext{
${ }^{1}$ Fell, Dafydd. 'Introduction.' In The Politics of Modern Taiwan. London Routledge, 2009.
} 
An Overview of the Practice and Study of Taiwan's Foreign Policy. ${ }^{2}$ Taken together these pieces have offered a critical overview of the development of research on Taiwan's domestic and international politics from the 1980s to the early 2000s. They were to be a key starting point for a number of Taiwan politics courses for well over a decade. ${ }^{3}$ There are also a number of important states of the fields in edited volumes, such as Tseng and Lin's review of migration studies and Keng, Schubert and Lin's review of the state of Taishang studies. ${ }^{4}$ However, the field of Taiwan Studies has developed significantly over the last decade and a half since the publication of the above influential pieces. A problem with many of the other state of the field essays in Taiwan Studies is that they are widely scattered among different edited volumes and journals.

We thus believe that this is a good time to bring together the first collection of Taiwan Studies state of the field articles. Therefore when it came to proposing central themes for the Second World Congress of Taiwan Studies, one of those we opted for was Taiwan Studies: The State of the Field. The conference was held in London at the SOAS, University of London in June 2015 and was co-organized by Academia Sinica and SOAS. It was the largest ever Taiwan Studies conference held in Europe and even today is still spoken about fondly. State of the field papers featured on numerous panels and covered a wide range of disciplines, giving the large audience a picture of how vibrant the field of Taiwan Studies had become in recent decades. We had a clear objective of making the conference the basis of a publication that would give readers a collection of state of the field articles written by leading figures in Taiwan Studies.

Following the conference our task as co-editors was how to turn what had been fine conference papers or presentations into a high quality academic publication. Our original intention had been an edited book publication. We began the process of identifying which papers to invite to revise for the publication and offered some initial guidance on revision. Meanwhile after the conference a critically important development occurred in the field, which were the preparations for launching the new International Journal of Taiwan Studies. Therefore, we decided that instead of a book we would propose a special edition in the new journal and submitted the revised conference papers for review.

\footnotetext{
${ }^{2}$ Rigger, Shelley (2002). 'Political Science and Taiwan's Domestic Politics: The State of the Field.' Issues and Studies 38 (4): pp. 49-92. Lee, Wei-chin (2004). 'Field of Dreams: An Overview of the Practice and Study of Taiwan's Foreign Policy.' Issues and Studies 40 (3/4): pp. 137-182.

${ }^{3}$ For example, they featured in the opening class reading lists for the courses Government and Politics in Taiwan as well as Taiwan's Politics and Cross Strait Relations at SOAS, University of London.

${ }^{4}$ Tseng Yen-fen and Lin Ping, 'Through the looking glass: migration into and out of Taiwan,' in Fell, Dafydd and Chiu, Kuei-fen and Lin, Ping, (eds.), (2013) Migration to and From Taiwan. London: Routledge, 12-24; Keng Shu, Gunter Schubert and Emmy Rui-hua Lin, 'Taiwan and globalization: reflections on the trajectory of Taishang studies,' in Fell, Dafydd and Chiu, Kuei-fen and Lin, Ping, (eds.), (2013) Migration to and From Taiwan. London: Routledge, 25-41.
} 
We should add that not all the state of the field essays from the conference appear in this edition. In some cases authors decided to publish elsewhere or decided they just did not have the time to turn their PowerPoint presentations or draft papers into full state of the field papers. In some other cases essays did not pass the strict review process of the journal. That said though we are delighted with the seven pieces included in this launching issue and one more to appear in the $2^{\text {nd }}$ issue. We hope you readers enjoy reading them and believe they will make an important contribution to the scholars and students in our field of Taiwan Studies.

We open this special issue with Scott Simon's 'Ontologies of Taiwan Studies, Indigenous Studies and Anthropology.' No scholar has published more extensively on Taiwan's indigenous peoples in European languages than Scott Simon. Thus we were pleased that he joined the Second World Congress of Taiwan Studies and this special issue. Although the literature on indigenous peoples in both English and Chinese has shown growing diversity in the last two decades, Simon notes the tenuous relationship between Indigenous Studies and Taiwan Studies. Scholars working on indigenous topics often feel marginalised within Taiwan Studies and some disciplines, such as political science appear to especially neglect Indigenous Peoples. Simon introduces much work published in Chinese that many nonChinese speaking readers may not be familiar with. His critical review of the field highlights key changes such as the impact of the rise of indigenous nationalisms and attempts by scholars to decolonise the study of Taiwan's Indigenous nations.

The second piece in this special launching issue is Paul Katz's 'Bridging the Gaps: Methodological Challenges in the Study of Taiwanese Popular Religion.' Katz has established himself as a leading expert on Taiwan's popular religious scene. In this essay, he surveys major works in this field from the past twenty years published both in Taiwan and abroad, especially focusing on temple cults and festivals and, to a lesser extent, voluntary religious movements performing spirit-writing rituals. He points out that the principal challenges are methodological vigour to cross the humanities and social science divide and plausible comparative perspectives to place Taiwan's vibrant religious traditions and current conditions within the East Asian context.

To follow the state of the field of popular religion, the third article is offered by Wang Fuchang on the field of Taiwan's Ethnic Relations. Wang has been devoted to researching the social and political construction of Taiwan's different ethnic identities and their respective ethnic movements for more than two decades. He is regarded as a leading scholar in Taiwan on this field within Taiwan studies. In this essay, he examines the emergence and development of Taiwan's ethnic relations literature in close connection to democracymaking process. Four phases of ethnic relations dynamics are identified and it is significant to discover that the discourse of "four ethnic groups of Holo, Hakka, Aborigines and Mainlanders" was created in the 1990s and then after 2000, the so-called "fifth ethnic group of the new immigrants" was then added to the ethnic relations theorizing. In conclusion, 
Wang poses the challenge to fully understand the connections between the old and new ethnic relations and their incurred inequalities and tensions.

In addition to political and economic miracles, another area where Taiwan has seen a miraculous degree of transformation is in the realm of gender rights. Having published her groundbreaking book Women's Movements in Twentieth Century Taiwan in 2009, we were also delighted that Doris Chang agreed to survey this field for us. ${ }^{5}$ Chang reviews a longer time period than the essays by political scientists in this issue, covering the whole post martial law era. Thus she takes the reader from the emergence of a recognized women's movement through to Taiwan's recent push for greater LGBT rights. Another difference is that while much of the work in political science is published in English, Chang reminds us how much of the feminist literature she reviews is published in Chinese. The two core areas under examination are studies on the women's movement and those on feminist ideologies and discourses.

The fifth state of the field essay is written jointly by Ho Ming-sho, Huang Chun-hao, and Yuan Chun-ta, titled The Institutionalizations of Social Movements Study in Taiwan. Ho is an active and prolific researcher in the field of social movements. In this essay, they assess the reciprocal interaction between social movements and the academic research in Taiwan since the 1980s. It discovers the multidisciplinary nature of many existing scholarly writings and traces those pioneering scholars in this field. By employing a quantitative descriptive analysis of the published journal articles in both Chinese and English languages, this reports draws a few interesting conclusions on the significant features of the publications, such as the principal participating disciplines, emphasis on case study of selected social movements, a research tendency is changing from the earlier attention on the emergence to more attention on the consequences. This essay also discovers a growing link between the existing writings and the dominant international theoretical paradigms. More significantly, they show that there have been common intellectual concerns among all scholars who work on Taiwan's social movements in both Taiwan and elsewhere.

We are delighted to include Rigger's 'Studies on Taiwan's Democracy and Democratization' in this special issue. Her Politics in Taiwan: Voting for Democracy was such a landmark in the way the academic community understand Taiwan's democratic transition. ${ }^{6}$ Moreover, this article is the perfect complement to her earlier 2002 Issues and Studies essay, as this allows her to focus on more recent publications. The fact the Rigger has decided to focus on a narrower subset of political studies on democracy in Taiwan also reflects the overall growth in the Taiwanese political studies field compared with 15 years earlier. It is clear from her essay that there has been a shift away from earlier studies that focused on why Taiwan democratised towards assessing how Taiwan's democracy performs. Rigger gives us a sense of the debate within the literature she has chosen to review between those that are more

\footnotetext{
${ }^{5}$ Doris Chang. Women's Movements in Twentieth Century Taiwan. Urbana: University of Illinois Press, 2009.

${ }^{6}$ Shelley Rigger. Politics in Taiwan: Voting for Democracy. London Routledge, 1999.
} 
positive and negative about the state of Taiwan's democracy, noting that critical assessments seem to be in the majority. She also notes the biased or partisan nature of some of these writings. Her review also shows that much of the work on how Taiwan's democracy operates focuses on critical analysis of the country's political institutions, such as the constitution, political parties and electoral system. A final trend Rigger highlights is the growing use of comparative analysis of democracy and how when looked at comparatively Taiwan's democracy is actually evaluated rather positively.

The final state of the field essay is Scott Kastner's 'International Relations Theory and the Relationship across the Taiwan Strait.' Like Rigger, Kastner takes a narrower and more focused approach than other earlier state of the field pieces. He examines the degree that scholars have applied international relations theories in studies on cross-Strait relations. A starting point for Kastner is Wu Yu-shan's article from 17 years earlier which had called for greater use of theory in studies of cross-Strait relations. ${ }^{7}$ While Kastner notes the much greater employment of international relations theory in the cross-Strait literature, he argues that in some areas, such as on the military balance of power, too much of the analysis remains under theorised and descriptive.

\footnotetext{
${ }^{7}$ Wu Yu-shan. 2000. 'Theorizing on Relations across the Taiwan Strait: Nine Contending Approaches.' Journal of Contemporary China. 9 (25): 407-428.
} 